\title{
Decrease of vascular endothelial growth factor in macrophages from long-term
} smokers

\author{
K. Nagai, T. Betsuyaku, Y. Ito, Y. Nasuhara and M. Nishimura
}

ABSTRACT: Vascular endothelial growth factor (VEGF), a survival factor for endothelial cells and a promoter of angiogenesis, is reportedly expressed in alveolar macrophages (AMs).

To investigate whether long-term smoking with age affects VEGF expression in AMs, bronchoalveolar lavage (BAL) was performed on 18 young and 23 older volunteers with various smoking histories. The expressions of VEGF and its functional receptor, fms-like tyrosine kinase (FIt)-1, were quantified in AMs by real-time RT-PCR and, further, the level of VEGF in BAL fluid was determined by ELISA.

VEGF mRNA in AMs demonstrated a 1.8-fold reduction in current smokers compared with nonsmokers in older subjects and, furthermore, a 1.5-fold downregulation in those with emphysema, although there was no difference between current smokers and nonsmokers among the young subjects. The downregulation in total VEGF mRNA was supported by the substantial reduction of VEGF121 and VEGF165 isoforms. However, in contrast, Flt-1 mRNA did not differ within the older groups, whereas it was upregulated in young current smokers compared with age-matched nonsmokers. VEGF in BAL fluid is significantly decreased in current smokers compared with nonsmokers, regardless of their age.

In conclusion, these data imply that the biological availability of vascular endothelial growth factor in alveolar macrophages is impaired in older current smokers with long-term smoking histories.

KEYWORDS: Ageing, apoptosis, bronchoalveolar lavage, chronic obstructive pulmonary disease, emphysema, smoking

$\mathbf{V}$ ascular endothelial growth factor (VEGF) is a potent morphogenic cytokine that modulates embryogenic angiogenesis and vasculogenesis [1]. VEGF is reportedly expressed in various cell types in the lung, such as epithelial cells, endothelial cells and macrophages [2]. The finding that VEGF is highly expressed in normal tissues, especially in the lungs, is of particular interest because it suggests that constitutive VEGF expression may be important in maintaining normal structural homeostasis in adults. The blockade of VEGF signals causes endothelial cell apoptosis and emphysema in rats [3], suggesting a critical role for VEGF signalling through VEGF receptor (VEGFR)-2 (kinase insert domaincontaining receptor (KDR)/foetal liver kinase (Flk)-1) and the participation of apoptosis in the pathogenesis of pulmonary emphysema. Indeed, human emphysema is associated with increased apoptosis and decreased VEGF [4]. Apoptosis and the removal of apoptotic cells are tightly coupled to the regulation of normal lung structure [5], and processes that disrupt or uncouple this balance may alter normal cell turnover, ultimately resulting in the induction of lung pathology and disease [6].

Alveolar macrophages (AMs), the resident mononuclear phagocytes of lung alveoli, are the first line in cell-mediated defence against exogenous agents in the lower respiratory tract [7]. An increase in the number of macrophages in smokers' lungs is implicated in the pathogenesis of pulmonary emphysema [8]. One of the important functions of macrophages is to phagocytose unwanted materials, such as dying cells. Changes in macrophage function can be a crucial component in compromised lung defence. For example, AMs from chronic obstructive pulmonary disease (COPD) patients are deficient in their ability to phagocytose apoptotic airway epithelial cells [9]. This may result in disruption of the normal clearance of apoptotic cells, leading to sustained inflammation and, consequently, contribution to the pathogenesis of pulmonary emphysema.

\section{AFFILIATIONS}

First Dept of Medicine, Hokkaido University School of Medicine,

Sapporo, Japan.

\section{CORRESPONDENCE}

T. Betsuyaku

First Dept of Medicine Hokkaido University School of Medicine

$\mathrm{N}-15$

W-7

Kita-ku

Sapporo

Japan

060-8638

Fax: 81117067899

E-mail: bytomoko@

med.hokudai.ac.jp

Received:

September 242004

Accepted after revision:

December 062004

SUPPORT STATEMENT

This study was supported by the Respiratory Failure Research Group of the Ministry of Health, Labor, and Welfare of Japan (M. Nishimura) and by scientific research grants from the Ministry of Education, Science, Culture, and Sports of Japan (13470125; M. Nishimura) and (14570532; T. Betsuyaku). 
The role of VEGF expressed in AMs has not been fully clarified. In monocyte/macrophage lineages, VEGF is uniquely mediated by the VEGFR-1 (fms-like tyrosine kinase (Flt)-1) [10], rather than by the VEGFR-2 (KDR/Flk-1), and it may act in an autocrine fashion. VANDIVIER et al. [11] has recently shown that SU5416, an inhibitor of the VEGF receptor tyrosine kinases 1 and 2, and neutralising antibodies against VEGF and VEGFR1/Flt-1 inhibit phagocytosis of apoptotic Jurkat T-cells by human monocyte-derived macrophages. Based on these findings, it is of great interest to investigate the expression of VEGF and its receptor, Flt-1, in AMs to explore the effects of smoking and/or ageing, which are the major factors in the development of pulmonary emphysema. In this study, bronchoalveolar lavage (BAL) was performed on young and older nonsmokers and current smokers, and, then, the expression of VEGF and Flt-1 in harvested AMs and the level of VEGF in BAL fluid were examined. To further assess the possible link with the development of early emphysema, the current authors then separately analysed data from the older current smokers that exhibited emphysematous changes on high-resolution computed tomography (HRCT) scans.

\section{METHODS}

\section{Subjects}

A total of 41 volunteers were recruited. The lifelong nonsmoker group consisted of nine young males and seven older males. The current smoker group included nine young males who had smoked for $<3$ yrs, and 16 older subjects, including one female, with smoking histories of $>20$ yrs. None of the subjects was on regular medication or had a history of asthma or other allergic disorders. To confirm the absence of disease, they were also given a physical examination, as well as pulmonary function tests, chest radiograph examination and blood tests. All subjects had a normal nutritional state and liver function, and no signs of inflammation. The plasma level of $\alpha_{1^{-}}$ protease inhibitor was also evaluated to exclude its deficiency. To objectively confirm the current smoking status, all subjects were examined for exhaled carbon monoxide levels using a CO analyser (Micro Smokerlyser; Bedfont, Rochester, UK). All older current smokers were screened for emphysematous changes by HRCT scans and scored as previously described $[12,13]$. Briefly, the percentage of the overall areas involving emphysematous changes was visually assessed and graded 15 as follows: 1) involvement of emphysematous changes $<5 \%$; 2) between 5 and $25 \%$; 3) between 25 and $50 \%$; 4) between 50 and $70 \%$; or 5 ) $>75 \%$ of the lung. A score of 0 was given if there were no emphysematous changes. All subjects gave written informed consent, and the study was approved by the ethics committee of Hokkaido University School of Medicine, Sapporo, Japan.

\section{$B A L$ and collection of $A M$}

All smokers had stopped smoking cigarettes for $\geqslant 12 \mathrm{~h}$ prior to the BAL procedure, in order to eliminate acute effects of smoking. Sequential BAL was performed as previously described [14]. Briefly, four separate 50-mL aliquots of sterile $0.9 \%$ saline were infused into the right middle lobe segment through a flexible fibreoptic bronchoscope (Model BF-B3R; Olympus, Tokyo, Japan). The fluid returned from the first 50$\mathrm{mL}$ aliquot was not used for this study. The remaining lavage fluid was combined and used as the alveolar lavage fluid-rich fraction. Cell pellets were counted in a haematocytometer, and Wright-Giemsa stain smears served to identify differential profiles after cytospin preparation. Differential counts were performed by examining $\geqslant 300$ cells using a standard light microscope as previously described [12]. AMs were adjusted to $1 \times 10^{6} \cdot \mathrm{mL}^{-1}$ and plated on poly-L-lysine-coated plastic wells (Corning, Big Flats, NY, USA) for $1 \mathrm{~h}$ at $37^{\circ} \mathrm{C}$ in RPMI-1640 medium (GIBCO, Grand Island, NY, USA). After two washes in PBS, the adherent cells were used for preparation of total RNA with guanidium thiocyanate using an Isogen RNA extraction kit (Nippon Gene, Tokyo, Japan) as previously described $[12,15]$. There were no neutrophils contaminated in any of these preparations of cells in culture.

\section{Quantitative RT-PCR for VEGF and Flt-1}

Reverse transcription was performed in the presence of Maloney leukaemia virus reverse transcriptase (Epicentre Technologies, Madison, WI, USA), and 5' exonuclease-based fluorogenic PCR was performed using ABI PRISM 7700 Sequence Detector (Applied Biosystems, Foster City, CA, USA) as described previously [15]. Assays-on-Demand Gene Expression probes were used for VEGF and Flt-1, and were derived from the boundary of exons 1 and 2 of the human VEGF gene sequence (GenBank accession number NM 003376; National Center for Biotechnology Information, Bethesda, MD, USA) and from the boundary of exons 17 and 18 of the human Flt-1 gene sequence (GenBank accession number NM 002019; National Center for Biotechnology Information), respectively (Applied Biosystems). Primers and a labelled probe for glyceraldehyde-3-phosphatase dehydrogenase (GAPDH) cDNA as an endogenous control were purchased (TaqMan human GAPDH control reagents; Applied Biosystems). Briefly, a 2$\mu \mathrm{L}$ aliquot of the cDNA generated by reverse transcription from macrophages was placed into each tube, and PCR was carried out using TaqMan Universal PCR Master Mix (Applied Biosystems) in a $20-\mu \mathrm{L}$ total volume. PCR was performed for 40 cycles, consisting of a denaturation step at $95^{\circ} \mathrm{C}$ for $15 \mathrm{~s}$ and a combined annealing and extension step at $60^{\circ} \mathrm{C}$ for $1 \mathrm{~min}$. For linear regression analysis of unknown samples in each assay, a standard curve was generated using eight- or 10-fold serial dilutions of cDNA from human AMs obtained from a normal control subject as described previously [16]. The relative amount of target mRNA in the samples was assessed by interpolation of their threshold cycles from a standard curve. Signal levels of VEGF or Flt-1 were normalised against GAPDH mRNA and were shown as a relative ratio.

\section{Analysis of VEGF mRNA isoforms}

Oligonucleotide primers spanning the insertion/deletion site of human VEGF165 were designed as described by MOHLE et al. [17]. The sense primer was 5'-CGAAGTGGTGAAGTTCATGGATG-3' and the antisense primer was 5'-TTCTGTATCAGTCTTTCCTGGTGAG-3'. RT-PCR of mRNA encoding the 121-, 165- and 189-amino acid isoforms of VEGF results in PCR products 403, 535 and 607 base pairs (bp), respectively [18]. Primers were also synthesised to amplify the cDNA encoding $\beta$-actin as an endogenous control [17]. The expected size of the PCR product was $513 \mathrm{bp}$. To carry out $\mathrm{PCR}, 5 \mu \mathrm{L}$ of the reverse transcription reaction was amplified by Taq DNA polymerase (Applied Biosystems) dissolved in 
a $20-\mu \mathrm{L}$ reaction containing $2.5 \mu \mathrm{M}$ deoxynucleotide triphosphates, $2.5 \mu \mathrm{L}$ PCR reaction buffer, $0.037 \mu \mathrm{mol} \mathrm{MgCl}_{2}$, and 25 pmol of VEGF primers or 12.5 pmol of $\beta$-actin primers. The PCR profile for VEGF consisted of the following: a 3-min initial denaturation at $95^{\circ} \mathrm{C} ; 30$ cycles of $30 \mathrm{~s}$ at $94^{\circ} \mathrm{C}$, $1 \mathrm{~min}$ at $62^{\circ} \mathrm{C}$ and $1 \mathrm{~min}$ at $72^{\circ} \mathrm{C}$; and a final incubation for $5 \mathrm{~min}$ at $75^{\circ} \mathrm{C}$. For $\beta$-actin, the PCR profile consisted of 25 cycles of $30 \mathrm{~s}$ at $94^{\circ} \mathrm{C}, 30 \mathrm{~s}$ at $55^{\circ} \mathrm{C}$ and $30 \mathrm{~s}$ at $72^{\circ} \mathrm{C}$, and a final incubation for $5 \mathrm{~min}$ at $75^{\circ} \mathrm{C}$. The PCR products were separated by $2 \%$ agarose gel electrophoresis.

\section{Measurement of soluble VEGF protein in BAL}

The level of VEGF in unconcentrated BAL fluid was assayed using an ELISA kit (Amersham, Little Chalfont, UK). The ELISA used in the current study was designed for the measurement of VEGF165 and VEGF121. The minimum concentration of VEGF detected by this method was $15.6 \mathrm{pg} \cdot \mathrm{mL}^{-1}$.

\section{Statistical analysis}

Group data are expressed as mean \pm SE or as the median (range) when appropriate. Differences between the two groups of the young subjects were analysed using an unpaired t-test. Between the older subject groups, statistical analysis was performed by single-factor ANOVA, and the Games/Howell test was applied as a post hoc test for multiple comparisons in ANOVA when appropriate. Statistical significance was set at $\mathrm{p}<0.05$.

\section{RESULTS \\ Characteristics of subjects}

Tables 1 and 2 summarise the clinical characteristics and BAL findings. The age of the young subjects ranged 20-29 yrs and the older subjects $47-77$ yrs. The subjects were classified into five groups according to age, smoking status and presence of emphysema on computed tomography (CT) scans. Emphysema, as detected on CT scans, occurred in $<25 \%$ of the total lung area in most subjects in the emphysema groups. Among the older groups, both current smokers with and without emphysema were significantly younger than the lifelong nonsmokers, and forced expiratory volume in one second (FEV1) \% pred and FEV1/vital capacity were significantly lower in current smokers with emphysema than in lifelong nonsmokers (table 1). The percentage recovery of

\section{TABLE 1 Clinical characteristics}

\begin{tabular}{|c|c|c|c|c|c|}
\hline & \multicolumn{2}{|c|}{ Young } & \multicolumn{3}{|c|}{ Older } \\
\hline & Lifelong nonsmokers & Current smokers & Lifelong nonsmokers & \multicolumn{2}{|c|}{ Current smokers } \\
\hline Subjects n & 9 & 9 & 7 & 9 & 7 \\
\hline Pack-yrs & 0 & $5 \pm 1$ & 0 & $45 \pm 4$ & $46 \pm 9$ \\
\hline VC \% pred & $100 \pm 4$ & $96 \pm 5$ & $122 \pm 8$ & $112 \pm 5$ & $100 \pm 8$ \\
\hline FEV $_{1} \%$ pred & $83 \pm 4$ & $88 \pm 4$ & $124 \pm 8$ & $104 \pm 4$ & $94 \pm 8$ \\
\hline FEV $_{1} /$ VC \% & $96 \pm 1$ & $87 \pm 2^{\#}$ & $84 \pm 2$ & $80 \pm 2$ & $76 \pm 3^{\circ}$ \\
\hline$D L$, co $\%$ pred & NA & NA & NA & $96 \pm 5$ & $84 \pm 7$ \\
\hline
\end{tabular}

Data are presented as $n$ and mean \pm SE. -: without; +: with; $\mathrm{VC}$ : vital capacity; FEV1: forced expiratory volume in one second; $D \mathrm{~L}, \mathrm{CO}$ : carbon monoxide diffusing capacity of the lung; NA: not available. \#: $p<0.05$ versus young lifelong nonsmokers; " $p<0.05$ versus older lifelong nonsmokers.

TABLE 2 Bronchoalveolar lavage (BAL) findings

\begin{tabular}{llll}
\multicolumn{2}{c}{ Young } & \multicolumn{2}{c}{ Older } \\
& Current smokers & Lifelong nonsmokers & Current smokers \\
\cline { 4 - 5 } & Emphysema - Emphysema +
\end{tabular}

\begin{tabular}{lcccc}
\hline & & & & \\
Recovery rate \% & $81 \pm 3$ & $66 \pm 3^{\#}$ & $71 \pm 4$ & $51 \pm 4^{*}$ \\
Albumin $\mathbf{~ m g} \cdot \mathrm{L}^{-1}$ & $56 \pm 12$ & $35 \pm 4$ & $55 \pm 10$ & $35 \pm 9$ \\
Total cells $\times \mathbf{1 0}^{\mathbf{4}} \cdot \mathbf{m L}^{-1}$ BAL fluid & $10 \pm 1$ & $17 \pm 3^{\#}$ & $13 \pm 1$ & $36 \pm 3$ \\
Macrophages $\times \mathbf{1 0}^{\mathbf{4}} \cdot \mathbf{m L}^{-1}$ BAL fluid & $9 \pm 1$ & $16 \pm 3^{\#}$ & $11 \pm 1$ & $32 \pm 7^{*}$ \\
Neutrophils $\times \mathbf{1 0}^{\mathbf{4}} \cdot \mathbf{m L}^{-1}$ BAL fluid & $0.1 \pm 0$ & $0.4 \pm 0.2$ & $0.04 \pm 0$ & $43 \pm 12^{*}$ \\
\hline
\end{tabular}

Data are presented as mean \pm SE. -: without; +: with. ${ }^{\#:} \mathrm{p}<0.05$ versus young lifelong nonsmokers; ${ }^{\bullet}: \mathrm{p}<0.05$ versus older lifelong nonsmokers. 

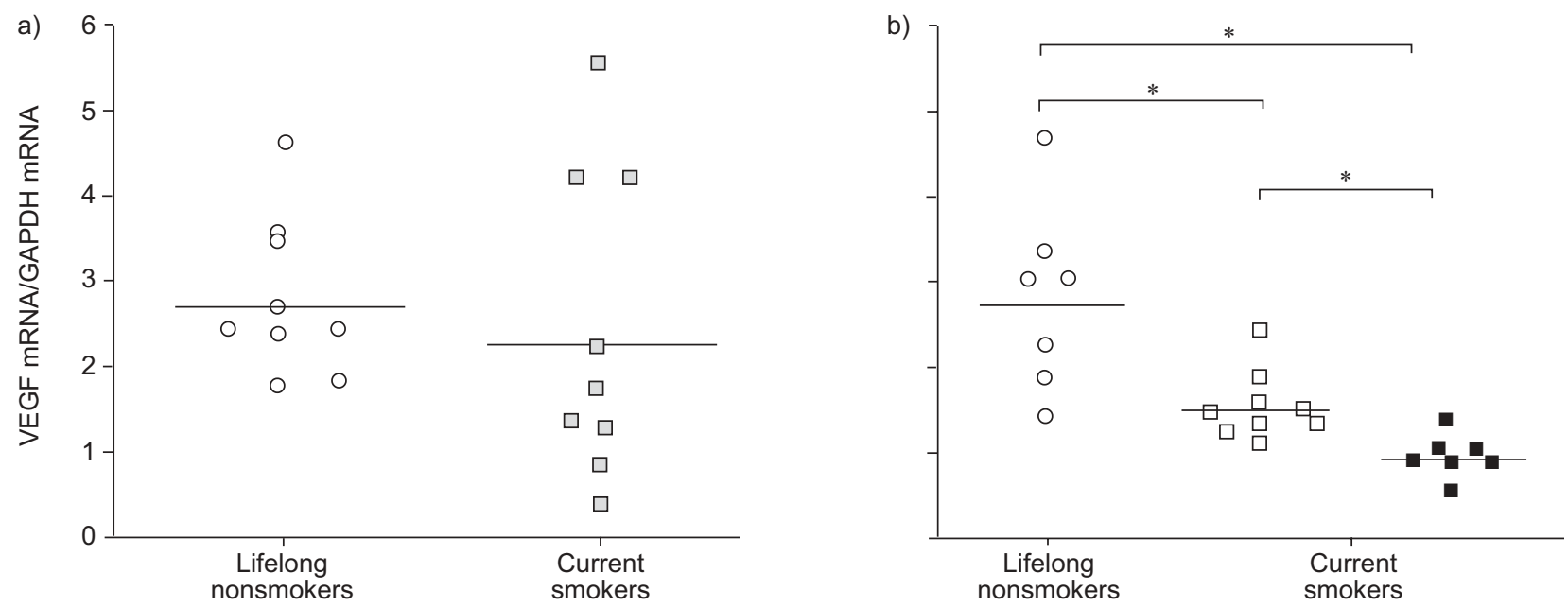

FIGURE 1. Level of vascular endothelial growth factor (VEGF) mRNA in alveolar macrophages (AMs) normalised by glyceraldehyde-3-phosphatase dehydrogenase (GAPDH) mRNA in a) young subjects and b) older subjects. Horizontal bars represent the mean. There was no significant difference between current smokers and lifelong nonsmokers among the young subjects. VEGF mRNA in AMs was significantly decreased in current smokers compared with lifelong nonsmokers in older subjects, and was further downregulated in those with emphysema ( $\square)$ as evidenced by high-resolution computed tomography scans. $\square$ : without emphysema. *: p<0.05.

instilled fluid was significantly lower in current smokers compared with nonsmokers of the same age, not only for the older group, but also for the younger group $(p<0.05)$. The concentration of albumin and neutrophil cell numbers in the BAL fluid was not statistically different between the groups, but the numbers of total cells and macrophages in BAL fluid were significantly increased $(\mathrm{p}<0.05)$ both in young and older current smokers compared with lifelong nonsmokers of the same age.

\section{Level of VEGF mRNA in AM}

As shown in figure 1, among older subjects, the normalised level of VEGF mRNA (to GAPDH mRNA) in the AMs was significantly decreased in current smokers without emphysema compared with lifelong nonsmokers (mean \pm SE $1.5 \pm 0.1$ versus $2.8 \pm 0.4 ; \mathrm{p}<0.05$ ). Furthermore, AMs from current smokers with emphysema demonstrated a significant downregulation of VEGF expression compared not only with lifelong nonsmokers $(1.0 \pm 0.1$ versus $2.8 \pm 0.4 ; \mathrm{p}<0.05)$, but also with current smokers without emphysema $(1.0 \pm 0.1$ versus $1.5 \pm 0.1 ; \mathrm{p}<0.05)$ of the same age. In contrast, VEGF expression in AMs did not significantly differ between lifelong nonsmokers and current smokers among young subjects $(2.8 \pm 0.3$ versus $2.4 \pm 0.6)$. There was a significant correlation between the level of VEGF mRNA/GAPDH mRNA in AMs and carbon monoxide diffusing capacity of the lung $(D \mathrm{~L}, \mathrm{CO})$ in subjects with emphysema $(r=0.84 ; \mathrm{p}<0.05$; fig. 2$)$, whereas no correlation was found between the level of VEGF mRNA/GAPDH mRNA in AMs and FEV1 (nonsignificant, $p=0.18$ ). The CT scores showed no relationship with the level of VEGF mRNA/ GAPDH mRNA in AMs.

\section{Expression of VEGF mRNA isoforms in AM}

To determine which isoforms of VEGF mRNA contribute to the reduction of the total VEGF expression in AMs, a semiquantitative RT-PCR analysis was performed. As shown in figure 3, AMs produced PCR products of 403 and $535 \mathrm{bp}$, corresponding to the 121- and 165-amino acid isoforms of VEGF, respectively. Expression of VEGF189 could barely be detected, even after 35 cycles of PCR (data not shown). PCR products for $\beta$-actin (513 bp) served as an endogenous control for each sample. The expressions of both VEGF121 and VEGF165 were substantially reduced in older current smokers with emphysema, supporting the results obtained by quantitative RT-PCR for total VEGF expression in AMs.

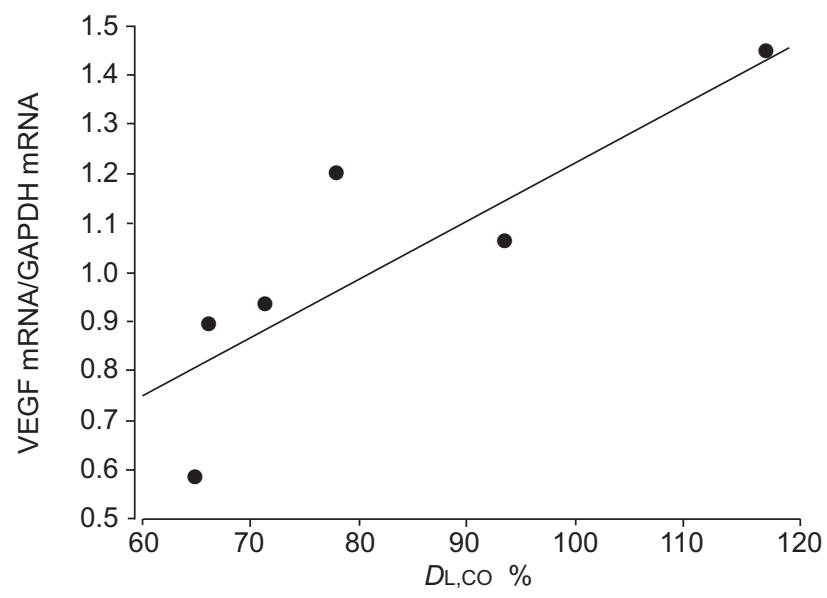

FIGURE 2. Relationship between the level of vascular endothelial growth factor (VEGF) mRNA/glyceraldehyde-3-phosphatase dehydrogenase (GAPDH) mRNA in alveolar macrophages (AMs) and carbon monoxide diffusing capacity of the lung $(D L, C O)$ in subjects with emphysema. The expression of VEGF in AMs was positively correlated with $D L, C O$ in subjects with emphysema $(n=7 ; p<0.05$; $r=0.84)$. 


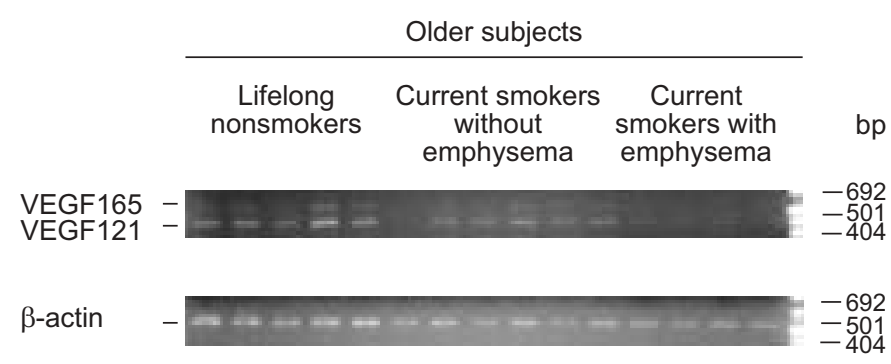

FIGURE 3. Vascular endothelial growth factor (VEGF) mRNA isoforms expressed in alveolar macrophages (AMs) from older subjects. Representative RT-PCR of mRNA for VEGF165 (535 bp) and VEGF121 (403 bp) isoforms in AMs from lifelong nonsmokers, current smokers without emphysema and current smokers with emphysema are shown. Amplification products for $\beta$-actin (530 bp) served as controls. The intensity of both bands is significantly lower in the current smokers with emphysema compared with the other groups.

\section{Level of Flt-1 mRNA in AM}

Flt-1 mediates functions of VEGF and regulates the levels of available VEGF through ligand entrapment in the alveolar space. To examine whether alterations in the expression of Flt- 1 are associated with ageing, smoking or the presence of emphysema, the normalised levels of Flt-1 mRNA were compared to GAPDH mRNA. Figure 4 shows that, in young groups, the expression of Flt-1 in AMs was significantly upregulated in current smokers compared with age-matched lifelong nonsmokers $(1.3 \pm 0.2$ versus $0.7 \pm 0.1 ; \mathrm{p}<0.05)$. In contrast, an upregulation of Flt-1 mRNA level was not observed in older current smokers whether or not emphysema was present.

\section{VEGF levels in BAL}

The level of VEGF protein in BAL fluid was evaluated (fig. 5). In young subjects, the level of VEGF in the BAL fluid decreased in current smokers compared with lifelong nonsmokers $\left(21 \pm 7\right.$ versus $\left.47 \pm 9 \mathrm{pg} \cdot \mathrm{mL}^{-1} ; \mathrm{p}<0.05\right)$, as it did in older subjects $\left(13 \pm 3\right.$ versus $\left.41 \pm 6 \mathrm{pg} \cdot \mathrm{mL}^{-1} ; \mathrm{p}<0.05\right)$. No difference was found, however, between older current smokers with or without emphysema $\left(12 \pm 4\right.$ versus $\left.13 \pm 3 \mathrm{pg} \cdot \mathrm{mL}^{-1}\right)$.

\section{DISCUSSION}

The presence of VEGF in normal AMs is of particular interest because it suggests that constitutive VEGF expression may be important in maintaining the physiological functions of AMs in the lungs. In the current study, it was demonstrated that, in older current smokers even without lung disease, VEGF expression in AMs was significantly lower than in older lifelong nonsmokers. In addition, VEGF expression in AMs was further downregulated in current smokers with emphysema compared not only with lifelong nonsmokers, but also with age-matched current smokers without emphysema. VEGF expression in AMs was also found to correlate positively with DL,CO in subjects with emphysema, indicating a possible relationship between lower expression of VEGF in AMs and parenchymal destruction in early emphysema. No correlation between VEGF expression in AMs and CT scores was observed, and it might not be surprising, since almost all the patients who were classified as having emphysema had emphysema comprising $<25 \%$ of the total area, if any, on CT scans.

In contrast, there was no difference in the expression of VEGF in AMs between young current smokers and young lifelong nonsmokers. Conversely, a significant upregulation of Flt-1 in AMs was observed in current smokers compared with age-matched lifelong nonsmokers for young but not older individuals. These data imply that the biological availability of VEGF in AMs may be impaired in older current smokers who have long-term smoking histories. In addition, the level of VEGF in BAL fluid was decreased in current smokers compared with lifelong nonsmokers, regardless of age, although no difference was found between current smokers with and without emphysema in older current smokers.
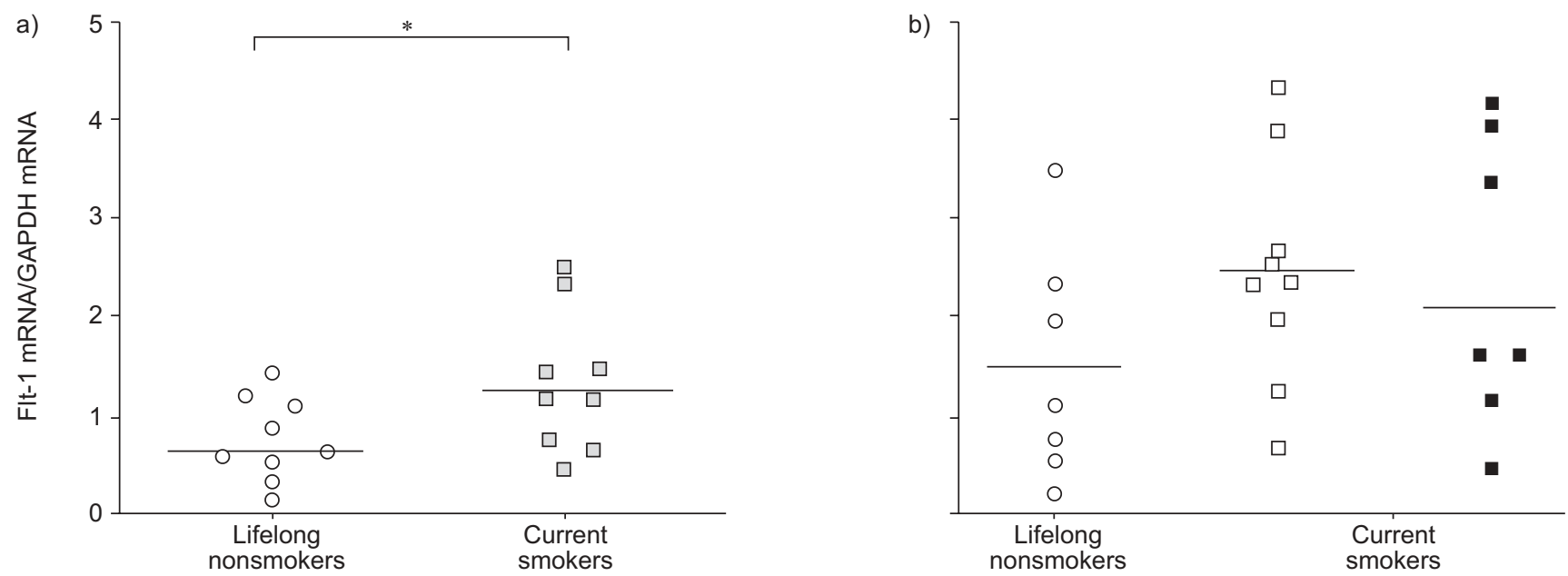

FIGURE 4. Level of fms-like tyrosine kinase (FIt)-1 mRNA in alveolar macrophages (AMs) normalised by glyceraldehyde-3-phosphatase dehydrogenase (GAPDH) mRNA in a) young subjects and b) older subjects. Horizontal bars represent the mean. The expression of Flt- 1 in AMs was significantly upregulated in current smokers compared with age-matched lifelong nonsmokers only in young subjects, but not in older subjects. $\square$ : without emphysema; $\mathbf{\square}$ : with emphysema. *: p<0.05. 

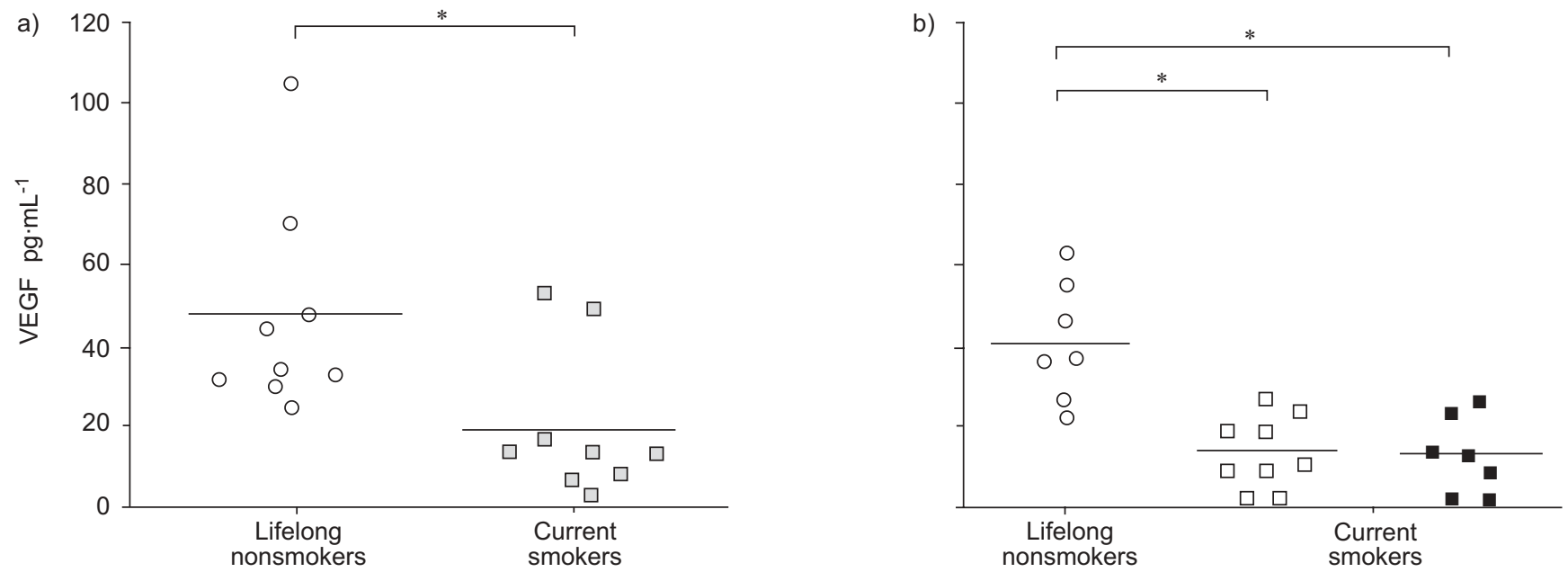

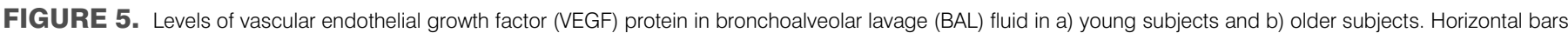
represent the mean. The level of VEGF in BAL fluid was decreased in current smokers compared with lifelong nonsmokers regardless of the age. $\square$ : without emphysema; with emphysema. *: $p<0.05$.

While VEGF is also expressed in other cell types, including endothelial cells, its specific downregulation in AMs may provide a clue to the role of AMs in the pathogenesis of pulmonary emphysema. Cell damage and apoptosis, in which VEGF plays a key role via the KDR/Flk-1, is constantly ongoing and presumably highly regulated to maintain homeostasis of the entire alveolar unit. The fact that apoptotic cells are frequently observed in the emphysematous lungs may indicate that, on a cellular level, there is also a failure of phagocytosis to remove dead cells [19]. Indeed, HoDGE et al. [9] revealed that AMs from subjects with COPD are deficient in their ability to phagocytose apoptotic airway epithelial cells. However, it is not certain whether this defect is associated with ageing, smoking or the presence of disease. Phagocytosis of apoptotic cells leads to VEGF upregulation in macrophages [20], and the phagocytosis of apoptotic cells in macrophages was inhibited by VEGFR-1-neutralising antibodies [11]. Therefore, VEGF expressed in AMs may have a vital role in regulating the normal clearance of apoptotic cells and, for this reason, its loss could contribute to the pathogenesis of emphysema and other pathogenic mechanisms in the lung.

Human VEGF occurs in several molecular variants, which arise by alternative splicing of a single mRNA. The current authors demonstrated that VEGF121 and VEGF165 are the dominant isoforms of VEGF expressed in adult AMs, and decreased expression of VEGF in AMs could be due to changes in both VEGF121 and VEGF165.

VEGF differentially modulates endothelial and nonendothelial cells because of functional differences or distinct receptor expression profiles. In contrast to endothelial cells, monocyte/macrophage cell lineages express only Flt-1 [10], which mediates the functions of VEGF and regulates the levels of available VEGF by ligand entrapment in the alveolar space. In the current study, it was found that Flt-1 expression is upregulated in AMs from young current smokers compared with those from young lifelong nonsmokers, but this upregulation was not seen in older current smokers. AMs from young smokers may be tolerant to chronic exposure to smoking by upregulating Flt-1, whereas persistent stimulation of smoking for the long term in older smokers may reduce the compensatory elevation of Flt-1 expression by AMs.

Age-associated alterations among smokers, such as in cytokine production and cellular metabolism, have been reported in the functional activities of AMs [21]. The increase in the production of oxygen radical species in AMs from current smokers is observed regardless of the age, whereas the activities of antioxidant enzymes are increased only in young smokers and, conversely, decreased in elderly smokers [22]. Using a standardised excisional injury model, SWIFT et al. [23] demonstrated that wound repair is substantially delayed in aged mice, and that the macrophages from the aged mice produced significantly less VEGF than those from the younger mice. In the current study, it was demonstrated that the effects of current smoking on VEGF and Flt-1 expression in AMs differ by age.

It should be noted that, with respect to VEGF expression, each cell type in the lung has different responses to cigarette smoke. A recent study by WRIGHT et al. [24] demonstrated the upregulation of VEGF and its receptor (KDR/Flk-1) in the pulmonary arteries of rats exposed to cigarette smoke. Enhanced expression of VEGF in the pulmonary arteries of smokers and patients with moderate COPD has also been reported [25]. Furthermore, cigarette smoke exposure upregulates the expression of VEGF in the airway epithelial cell line BEAS-2B in vitro [26]. In contrast, several reports indicate that VEGF is downregulated by cigarette smoke in lung cells. Cigarette smoke decreases VEGF and VEGFR expression in cultured cells, such as the monocytic U937 and the lung carcinoma A549 cell lines, and triggers apoptosis of pulmonary endothelial cells [27]. Also, cigarette smoke exposure impairs angiogenesis by inhibiting VEGF through decreased expression of hypoxia inducible factor- $1 \alpha$ under hypoxic conditions [28]. However, the understanding of the rate and sites of production of VEGF in various lung cells and its concentration 
in BAL fluid, sputum and blood is still insufficient in smokingrelated conditions.

The adult lung contains abundant VEGF protein that can be released from matrix or cellular stores. Smoking reportedly reduces the level of VEGF in BAL fluid [29]. Ageing may be another factor that influences the levels of VEGF in BAL fluid [30]. One of the major problems of working with an aged population is defining the categories because they have a variety of smoking histories. In the current study, older lifelong nonsmokers and current smokers with long-term smoking histories were selected. Whilst the fact that smokers with or without emphysema were younger than older lifelong nonsmokers was unfortunate, this is unlikely to have affected the results, as others have demonstrated that VEGF appears to decrease with age [30]. It was found that a decrease in the level of VEGF in BAL fluid is strongly associated with current smoking exposure that was not associated with the presence of emphysematous changes on CT scans. All of the subjects were asymptomatic, and none of them conformed to the diagnosis of chronic bronchitis. Furthermore, the severity of emphysema was low, and the disease was heterogeneously distributed. The concentration of VEGF in induced sputum is substantially higher in patients with asthma and chronic bronchitis, but lower in patients with emphysema [31]. The possibility that the VEGF level in BAL fluid might be lower in individuals with more advanced emphysema cannot be ruled out. Regardless, one might speculate that the decreased VEGF in the lower respiratory tract may lead to impaired structure homeostasis in the lung, particularly if one considers that VEGF signalling plays an important role in the clearance of apoptotic cells by AMs.

There have been few studies comparing the effects of long- and short-term smoking on alveolar macrophages from humans. It is important to understand the phenotypes of cells from older long-term smokers because smoking-related diseases are often found in this age group. There is no evidence as to whether vascular endothelial growth factor expression or its signalling directly regulate the phagocytic machinery of macrophages in vivo. However, considering the accumulation of alveolar macrophages in the early stage of destructive regions of pulmonary emphysema, the current authors' findings suggest that vascular endothelial growth factor deficiency in alveolar macrophages has a pathological significance in long-term smokers.

\section{REFERENCES}

1 Flamme I, Frolich T, Risau W. Molecular mechanisms of vasculogenesis and embryonic angiogenesis. J Cell Physiol 1997; 173: 206-210.

2 Berse B, Brown LF, Van de Water L, Dvorak HF, Senger DR. Vascular permeability factor (vascular endothelial growth factor) gene is expressed differently in normal tissues, macrophages, and tumors. Mol Biol Cell 1992; 2: 211220.

3 Kasahara Y, Tuder RM, Taraseviciense-Stewart L, et al. Inhibition of VEGF receptors causes lung cell apoptosis and emphysema. J Clin Invest 2000; 106: 1311-1319.

4 Kasahara Y, Tuder RM, Cool CD, Lynch DA, Flores SC, Voelkel NF. Endothelial cell death and decreased expression of vascular endothelial growth factor receptor 2 in emphysema. Am J Respir Crit Care Med 2001; 163: 737-744.

5 Fadok VA, Bratton DL, Rose DM, Pearson A, Ezekewitz RAB, Henson PM. A receptor for phosphatidylserine-specific clearance of apoptotic cells. Nature 2000; 405: 85-90.

6 Voelkel NF, Cool CD. Pulmonary vascular involvement in chronic obstructive pulmonary disease. Eur Respir J 2003; 22: Suppl. 46, S28-S32.

7 Zhang P, Summer WR, Bagby GJ, Nelson S. Innate immunity and pulmonary host defense. Immunol Rev 2000; 173: 39-51.

8 Shapiro SD. The macrophage in chronic obstructive pulmonary disease. Am J Respir Crit Care Med 1999; 160: S29-S32.

9 Hodge S, Hodge G, Scicchitano R, Reynolds PN, Holmes M. Alveolar macrophages from subjects with chronic obstructive pulmonary disease are deficient in their ability to phagocytose apoptotic airway epithelial cells. Immunol Cell Biol 2003; 81: 289-296.

10 Clauss M, Weich H, Breier G, et al. The vascular endothelial growth factor receptor Flt-1 mediates biological activities. Implications for a functional role of placenta growth factor in monocyte activation and chemotaxis. J Biol Chem 1996; 271: 17629-17634.

11 Vandivier RW, Tuder RM, Morimoto K, Voelkel NF, Henson PM. Vascular endothelial growth factor regulates clearance of apoptotic cells: implications for emphysema. Am J Respir Crit Care Med 2004; 169: A503.

12 Betsuyaku T, Yoshioka A, Nishimura M, Miyamoto K, Kondo T, Kawakami Y. Neutrophil elastase associated with alveolar macrophages from older volunteers. Am J Respir Crit Care Med 1995; 151: 436-442.

13 Betsuyaku T, Yoshioka A, Nishimura M, Miyamoto K, Kawakami Y. Pulmonary function is diminished in older asymptomatic smokers and ex-smokers with low attenuation areas on high-resolution computed tomography. Respiration 1996; 63: 333-338.

14 Betsuyaku T, Kuroki Y, Nagai K, Nasuhara Y, Nishimura M. Effects of ageing and smoking on SP-A and SP-D levels in bronchoalveolar lavage fluid. Eur Respir J 2004; 24: 964-970.

15 Betsuyaku T, Takeyabu K, Tanino M, Nishimura M. Role of secretory leukocyte protease inhibitor in the development of subclinical emphysema. Eur Respir J 2002; 19: 1051-1057.

16 Betsuyaku T, Tanino M, Nagai K, Nasuhara Y, Nishimura M, Senior RM. Extracellular matrix metalloproteinase inducer is increased in smokers' bronchoalveolar lavage fluid. Am J Respir Crit Care Med 2003; 168: 222227.

17 Mohle R, Green D, Moore MA, Nachman RL, Rafii S. Constitutive production and thrombin-induced release of vascular endothelial growth factor by human megakaryocytes and platelets. Proc Natl Acad Sci USA 1997; 94: 663-668.

18 Houck KA, Ferrara N, Winter J, Cachianes G, Li B, Leung DW. The vascular endothelial growth factor family: identification of a fourth molecular species and 
characterization of alternative splicing of RNA. Mol Endocrinol 1991; 12: 1806-1814.

19 Wagner PD. Vascular endothelial growth factor and the pathogenesis of emphysema. Am J Med 2003; 114: 413414.

20 Golpon HA, Fadok VA, Taraseviciene-Stewart L, et al. Life after corpse engulfment: phagocytosis of apoptotic cells leads to VEGF secretion and cell growth. FASEB J 2004; 18 : 1716-1718.

21 Lioberas J, Celada A. Effect of aging on macrophage function. Exp Gerontol 2002; 37: 1323-1329.

22 Kondo T, Tagami S, Yoshioka A, Nishimura M, Kawakami Y. Current smoking elderly men reduces antioxidants in alveolar macrophages. Am J Respir Crit Care Med 1994; 149: 178-182.

23 Swift ME, Kleinman HK, DiPietro LA. Impaired wound repair and delayed angiogenesis in aged mice. Lab Invest 1999; 79: 1479-1487.

24 Wright JL, Tai H, Dai J, Chung A. Cigarette smoke induces rapid changes in gene expression in pulmonary arteries. Lab Invest 2002; 82: 1391-1398.

25 Santos S, Peinado VI, Ramirez J, et al. Enhanced expression of vascular endothelial growth factor in pulmonary arteries of smokers and patients with moderate chronic obstructive pulmonary disease. Am J Respir Crit Care Med 2003; 167: 1250-1256.
26 Koyama S, Sato A, Tsukadaira M, et al. Vascular endothelial growth factor mRNA and protein expression in airway epithelial cell lines in vitro. Eur Respir J 2002; 20: 1449-1456.

27 Tuder RM, Wood K, Taraseviciene L, Flores SC, Voekel NF. Cigarette smoke extract decreases the expression of vascular endothelial growth factor by cultured cells and trigger apoptosis of pulmonary endothelial cells. Chest 2000; 117: Suppl. 1, S241-S242.

28 Michaud SE, Menard C, Guy LG, Gennaro G, Rivard A. Inhibition of hypoxia-induced angiogenesis by cigarette smoke exposure: impairment of the HIF-1 alpha/VEGF pathway. FASEB J 2003; 17: 1150-1152.

29 Koyama S, Sato E, Haniuda M, Numanami H, Nagai S, Izumi T. Decreased level of vascular endothelial growth factor in bronchoalveolar lavage fluid of normal smokers and patients with pulmonary fibrosis. Am J Respir Crit Care Med 2002; 166: 382-385.

30 Mayer KC, Cardoni A, Xiang ZZ. Vascular endothelial growth factor in bronchoalveolar lavage from normal subjects and patients with diffuse parenchymal lung disease. J Lab Clin Med 2000; 135: 332-338.

31 Kanazawa H, Asai K, Hirata K, Yoshikawa J. Possible effects of endothelial growth factor in the pathogenesis of chronic obstructive pulmonary disease. Am J Med 2003; 114: 354-358. 